\title{
Effect of maternal heat stress during the dry period on growth and metabolism of calves
}

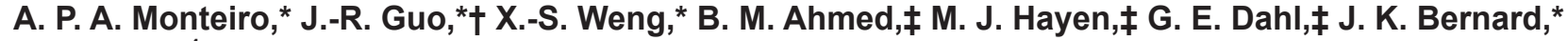 \\ and S. Tao*1 \\ *Department of Animal and Dairy Science, University of Georgia, Tifton 31793 \\ †College of Animal Science and Veterinary Medicine, Heilongjiang Bayi Agricultural University, Daqing, China 163319 \\ ‡Department of Animal Sciences, University of Florida, Gainesville 32611
}

\section{ABSTRACT}

Preliminary studies suggest that maternal heat stress (HS) during late gestation exerts carryover effects on a calf's insulin response after weaning, but a comprehensive evaluation of how maternal HS affects calf intake, growth, and metabolic response from birth to weaning is lacking. Our objective was to evaluate the effects of maternal HS during the dry period on dry matter intake, growth, and metabolism from birth to weaning. After birth, 20 heifers born to either HS $(\mathrm{n}=10)$ or cooled $(\mathrm{CL}, \mathrm{n}=10)$ dry cows were immediately separated from their dams and fed $3.8 \mathrm{~L}$ of colostrum from a common pool within $4 \mathrm{~h}$ of birth. All heifers were managed identically and weaned at $49 \mathrm{~d}$ of age (DOA). Calf starter intake was recorded daily, and body weight was assessed at birth and every 2 wk from birth to 56 DOA. Blood samples were collected twice a week until 56 DOA to assess hematocrit and concentrations of insulin and metabolites. To evaluate metabolic responses to maternal HS, a glucose tolerance test, insulin, and epinephrine challenge were performed on 3 consecutive days for all heifers at 8, 29, and 57 DOA. Maternal HS during the dry period did not affect heifer birth weight. Compared with HS, CL calves consumed more starter $(0.53$ vs. $0.34 \mathrm{~kg} / \mathrm{d})$ from birth to 56 DOA and were heavier (71.7 vs. $61.4 \mathrm{~kg}$ ) at 56 DOA. Relative to HS calves, CL calves tended to have higher hematocrit (27.4 vs. $24.7 \%)$. No differences were found between treatments in plasma concentrations of insulin and glucose, but HS calves had higher nonesterified fatty acids and $\beta$-hydroxybutyrate concentrations after 32 DOA. Compared with CL, HS calves had a faster glucose clearance after a glucose tolerance test and a slower insulin clearance after an insulin challenge. In conclusion, maternal HS during late gestation reduces calf starter

Received November 20, 2015

Accepted January 24, 2016.

${ }^{1}$ Corresponding author: stao@uga.edu intake and growth, alters blood metabolite profile, and increases noninsulin-dependent glucose uptake.

Key words: heat stress, glucose metabolism, dairy calves

\section{INTRODUCTION}

Heat stress (HS) during the dry period has tremendous effects on a cow's lactational performance in the subsequent lactation and on her immune competence and metabolic adaptation during the transition period (do Amaral et al., 2010, 2011; Tao et al., 2012b). Additionally, the effects of late gestation maternal HS are carried over to postnatal life of the calf. Previous studies indicate that a calf that experiences in utero HS has impaired passive and cell-mediated immune function before weaning (Tao et al., 2012a; Monteiro et al., 2014), suggesting that maternal HS during the dry period compromises the health of the offspring. Late gestation HS also exerts long-term effects on progeny performance up to and through the first lactation. Indeed, heifers born to heat-stressed dams have a greater chance of leaving the herd before puberty due to sickness, malformation, or growth retardation compared with those from cooled dry cows (Monteiro et al., 2013). Interestingly, heifers born to HS dry cows also had a greater number of services per conception confirmed 30 d after insemination and lower milk production in the first lactation relative to those from CL cows (Monteiro et al., 2013). However, the physiological mechanisms of the effects of maternal thermal insult on postnatal performance of the offspring are not clear.

Maternal HS also alters postnatal metabolism of the offspring. Lambs born to ewes heat stressed in mid gestation develop higher insulin response to glucose (Yates et al., 2011) and lower lipolytic response to adrenergic stimulation compared with those from thermoneutral dams (Chen et al., 2010). In the dairy calf, although growth rates were similar during the prepubertal period (Monteiro et al., 2013), calves born to HS dry cows have enhanced glucose uptake after weaning, as evi- 
denced by more rapid glucose clearance after a glucose tolerance test (GTT) and an insulin challenge (IC; Tao et al., 2014). However, it is unknown if this altered glucose metabolism after weaning by prenatal HS is developed in utero or during the postnatal stage due to variable nutrient consumption. Tao and Dahl (2013) observed that calves born to HS dry cows had a higher serum insulin concentration after colostrum ingestion during the first days of life compared with those from CL cows, which suggests a stronger pancreatic response to colostral lactose ingestion or a greater insulin resistance in peripheral tissues. Additionally, the effects of maternal HS on calf starter intake, blood metabolites, and insulin during the preweaning period are unknown. Our hypothesis was that maternal HS during the dry period alters calf metabolism during the preweaning period. The objective of the present study was to examine the effect of maternal HS during late gestation on heifer calf dry matter intake, growth, and metabolism.

\section{MATERIALS AND METHODS}

\section{Animals and Experimental Design}

The University of Florida Institute of Food and Agricultural Sciences Animal Research Committee approved the treatments and animal handling before beginning the trial. The animal study was conducted at the Dairy Unit and Calf Unit of the University of Florida from August to December, 2014. Briefly, at approximately $45 \mathrm{~d}$ before expected calving, multiparous Holstein cows were dried-off and randomly assigned to 1 of 2 groups, HS or cooling (CL), based on parity and mature equivalent milk production of the just completed lactation. All cows were housed in the same barn, but the stall areas for CL cows were equipped with fans and soakers, whereas those for HS were not. The ambient temperature and relative humidity in the stall areas for HS and CL cows were measured every 15 min by Hobo Pro Series Temp probes (Onset Computer Corporation, Pocasset, MA) during the entire dry period, and the temperature-humidity index was calculated based on Dikmen et al. (2008). Rectal temperature was assessed $(1430 \mathrm{~h})$ and respiratory rate was determined $(1500 \mathrm{~h})$ on a daily basis during the dry period.

Only heifer calves (HS, $\mathrm{n}=10$ and CL, $\mathrm{n}=10$ ) were enrolled in the current study. After calving, all calves were immediately removed from their dams and fed $3.8 \mathrm{~L}$ of colostrum from the same pool within $4 \mathrm{~h}$ after birth by esophageal feeder. Calves were housed in individual wire hutches on sand bedding and managed in the same manner thereafter. The day of birth was considered as $0 \mathrm{~d}$ of age (DOA). One heifer born to the HS dam suddenly died due to unknown reasons at 6 DOA, but the data collected before death were still included in the statistical analyses.

\section{Intake, Growth Measures, and Sample Collection}

From 1 DOA, calves were fed $6 \mathrm{~L} / \mathrm{d}$ of pasteurized milk divided into 2 equal feedings, in the morning (0700 $\mathrm{h})$ and in the afternoon $(1700 \mathrm{~h})$, until $41 \mathrm{DOA}$, and then only in the morning $(3 \mathrm{~L} / \mathrm{d})$ until weaning at 49 DOA. Samples of pasteurized milk were collected thrice weekly (AM and PM; Sunday, Tuesday, Thursday) throughout the study and analyzed for concentrations of lactose $(4.7 \pm 0.32 \%)$, fat $(3.25 \pm 0.42 \%)$, protein $(3.37 \pm 0.24 \%)$, and SCC $\left(855 \pm 447 \times 10^{3} / \mathrm{mL}\right)$ by a Bentley 2000 NIR analyzer at the DHIA Laboratory (Belleview, FL). Calf starter (Cornerstone, Purina Feed, Grey Summit, MO) and water were offered ad libitum starting at 1 DOA. The amount of starter offered and refused $(\sim 10 \%)$ were recorded daily for each calf. Samples of the starter were collected once weekly and dried at $55^{\circ} \mathrm{C}$ for $48 \mathrm{~h}$ to determine the moisture content.

The BW, withers height, heart girth, and hip height were measured at birth, 14, 28, 42, and 56 DOA, before morning feeding to evaluate growth. Blood samples were collected via jugular venipuncture into sodiumheparinized Vacutainer tubes (Becton Dickinson, Franklin Lakes, NJ) at 1, 4, 7, 11, 14, 18, 21, 25, 28, $32,35,39,42,46,49,53$, and 56 DOA before morning feeding and immediately placed in ice. Hematocrit was assessed and then samples were centrifuged at 2,619 $\times$ $g$ at $4^{\circ} \mathrm{C}$ for 30 min and plasma collected.

\section{Metabolic Tests}

All heifers were subjected to the metabolic tests consisting of an intravenous GTT, IC, and adrenaline challenge (AC) at 8, 29, and 57 DOA. The 3 metabolic tests were performed on 3 consecutive days in a randomized sequence. The actual dates were not different between treatments $(P>0.7)$ and averaged $8.8 \pm 0.4$, $30.1 \pm 0.4$, and $58.0 \pm 0.5 \mathrm{DOA}$ for GTT; $8.9 \pm 0.4$, $30.0 \pm 0.4$, and $58.1 \pm 0.5 \mathrm{DOA}$ for IC; and $9.1 \pm 0.3$, $30.7 \pm 0.3$, and $58.1 \pm 0.4 \mathrm{DOA}$ for AC. Animals were fasted overnight before the metabolic tests. A catheter (16 gauge $\times 7.5 \mathrm{~cm}$, Extended Use MILACATH, MILA International Inc., Erlanger, KY) was inserted into a jugular vein of each calf at least $1 \mathrm{~h}$ before the first metabolic test.

During GTT, $0.3 \mathrm{~g} / \mathrm{kg}$ of BW (Stanley et al., 2002; Yari et al., 2010) of glucose (dextrose 50\%, wt/vol; Phoenix Scientific Inc., St. Joseph, MO) was infused 
into a jugular vein through the catheter followed by 10 $\mathrm{mL}$ of sterile saline solution to flush the catheter. The dose of the glucose infusion will create a hyperglycemic status of the calves to study the glucose clearance and insulin responsiveness. Blood samples were drawn through the catheter, at $-15,-5$, and 0 min relative to the starting point of glucose infusion and 5, 10, 15, $20,30,40,50,60,75,90$, and 120 min relative to the ending point of glucose infusion, into Vacutainer tubes containing sodium fluoride and potassium oxalate (Becton Dickinson). Samples were immediately placed in ice followed by centrifugation at $2,619 \times g$ at $4^{\circ} \mathrm{C}$ for $15 \mathrm{~min}$ to collect plasma. The catheter was flushed with sterile saline containing sodium heparin between samplings to avoid clotting and the first $2 \mathrm{~mL}$ of blood collected was discarded before each sampling.

The procedures and bleeding regimens for IC and AC were similar to GTT, except that $0.1 \mathrm{IU}$ of insulin $/ \mathrm{kg}$ of $\mathrm{BW}(100 \mathrm{IU} / \mathrm{mL}$, human insulin, rDNA origin, Eli Lilly and Company, Indianapolis, IN) was administrated during IC to create a hyperinsulinemia for examination of insulin, glucose, and nonesterified fatty acid (NEFA) clearance (Hostettler-Allen, et al., 1994), and $1.4 \mu \mathrm{g}$ of epinephrine $/ \mathrm{kg}$ of BW $(1 \mathrm{mg} / \mathrm{mL}$, International Medication Systems, Limited, South El Monte, CA) was infused during AC (Baumgard et al., 2011).

\section{Insulin and Metabolite Analyses}

Plasma concentrations of glucose (Autokit Glucose, Wako Chemicals USA Inc., Richmond, VA), NEFA [HR Series NEFA-HR(2), Wako Chemicals USA Inc.], and BHB (Autokit 3-HB, Wako Chemicals USA Inc.) were determined by colorimetric methods, and the inter- and intraassay coefficients of variation were 6.6 and $3.2 \%$, 6.1 and $2.3 \%$, and 7.8 and $7.8 \%$, respectively. Insulin concentrations in the plasma were measured by RIA (Malven et al., 1987), and the inter- and intraassay coefficients of variation were 10 and $7.1 \%$, respectively.

\section{Calculation and Statistical Analyses}

The UNIVARIATE procedure of SAS 9.4 (SAS Institute Inc., Cary, NC) was used to analyze the composition of pasteurized milk, and the means \pm standard deviation are reported. The dry period and gestation lengths of the dams and the heifer DOA at each metabolic test were subjected to ANOVA using the GLM procedure of SAS 9.4 and the least squares means \pm standard error of the mean are reported. Repeated measures data, such as starter intake, growth measures, hematocrit, and plasma concentrations of metabolites and insulin, were analyzed using the MIXED procedure of SAS 9.4. The statistical model included fixed effects of treatment, time, and treatment by time with calf (treatment) as the random effect and the least squares means \pm standard error of the means were reported.

For the metabolic tests analyses, the average concentration of a metabolite or insulin for the samples collected at $-15,-5$, and 0 min related to the infusion was used as a baseline value. The increment/decrement of metabolites and insulin of a metabolic test were calculated by subtracting the baseline value from the maximal/minimal value of a metabolic test. The area under curve (AUC) between times was calculated based on the trapezoidal method, in which the metabolite or insulin concentration value was calculated by subtracting the baseline value from the actual value. The accumulated AUC of metabolites and insulin were calculated from 5 to $30 \mathrm{~min}, 5$ to $60 \mathrm{~min}$, and 5 to 120 min for all metabolic tests. The glucose concentrations from 5 to $60 \mathrm{~min}$ of the GTT and the insulin concentrations from 5 to $40 \mathrm{~min}$ of the IC were fitted as exponential curves using NLIN procedure of SAS 9.4, and the clearance rate (CR) and time to reach half of the maximal concentrations $\left(\mathrm{T}_{1 / 2}\right)$ were calculated based on Hayirli et al. (2001): CR $(\% / \mathrm{min})=100 \times$ $\left(\ln \left[\mathrm{t}_{\mathrm{a}}\right]-\ln \left[\mathrm{t}_{\mathrm{b}}\right]\right) /\left(\mathrm{t}_{\mathrm{b}}-\mathrm{t}_{\mathrm{a}}\right) ; \mathrm{T}_{1 / 2}(\mathrm{~min})=100 \times[\ln (2)] / \mathrm{CR}$, where $\left[t_{a}\right]$ and $\left[t_{b}\right]$ are the concentrations of metabolites or insulin at time a and b, respectively.

Measures of metabolic tests (baseline, maximum, minimum, increment/decrement, $\mathrm{CR}, \mathrm{T}_{1 / 2}$, and accumulated AUC) were analyzed by the MIXED procedure of SAS 9.4. The statistical model included fixed effects of treatment, DOA, and treatment by DOA with calf (treatment) as the random effect, and the least squares means \pm standard error of the means were reported. For each metabolic test within each test day, the plasma concentration of metabolites and insulin were analyzed using the MIXED procedure of SAS 9.4. The SAS model included fixed effects of treatment, minutes relative to infusion, and treatment by minutes relative to infusion with calf (treatment) as the random effect, and the baseline value of metabolites or insulin was included in the SAS model as covariates. The least squares means \pm standard error of the means were reported. Significance and tendency were declared when $P \leq 0.05$ and $0.05<P \leq 0.10$, respectively.

\section{RESULTS}

\section{Data of the Dams}

Cows involved in the current experiment were from a larger study (B. M. Ahmed and G. E. Dahl, unpub- 
lished). Briefly, the temperature-humidity index in the stall areas for dry cows were similar between treatments and averaged 77.7; however, HS cows had higher rectal temperature $\left(39.28\right.$ vs. $38.95^{\circ} \mathrm{C}, \mathrm{SEM}=0.02^{\circ} \mathrm{C}, P<$ 0.01 ) and respiration rate (66.7 vs. 49.1 breaths/min, $\mathrm{SEM}=3.3$ breaths $/ \mathrm{min}, P<0.01)$ compared with $\mathrm{CL}$ cows. Both groups of cows had similar gestation length (HS: $276.3 \mathrm{~d}$; CL: $276.1 \mathrm{~d}$, SEM $=2.0 \mathrm{~d}$ ), and dry period length (HS: $41.8 \mathrm{~d}$; CL: $41.5 \mathrm{~d}$, SEM $=0.9 \mathrm{~d}$ ).

\section{Growth and Intake}

No differences $(P>0.15)$ were observed in birth weight, and the average BW, withers height, heart girth, and hip height during the preweaning period between calves born to HS or CL cows (Table 1). However, a treatment by time interaction $(P<0.01)$ was found for BW from birth to 56 DOA, such that CL calves were heavier $(P<0.01)$ at 56 DOA compared with HS calves. As a result, the ADG was lower $(P$ $<0.05$ ) for HS calves from 29 to $56 \mathrm{DOA}$ and from 0 to 56 DOA, but similar $(P=0.24)$ from 0 to 28 DOA compared with CL calves. The amount of starter intake was considerable only after 4 wk of age (Figure 1). Calves born to HS cows consumed less (treatment by time interaction: $P<0.01)$ starter from 5 to $8 \mathrm{wk}$ of age compared with those from CL cows.

\section{Hematocrit, Insulin, and Metabolite Concentrations}

Compared with CL, calves born to HS cows tended $(P=0.07)$ to have a lower hematocrit from 1 to 56 DOA (Figure 2). No treatment effects $(P>0.30)$ were observed for basal plasma insulin or glucose concentrations from 1 to 56 DOA (Figure 3), but a tendency ( $P$ $=0.07$ ) was observed for a treatment by time interaction for plasma glucose such that HS calves had lower glucose concentration at 14,25 , and 53 DOA compared with CL calves. Compared with CL, HS calves had

Table 1. Birth weight, grain intake, and growth performance from birth to $56 \mathrm{~d}$ of age of calves born to dams exposed to either heat stress $(\mathrm{n}=10)$ or cooling $(\mathrm{n}=10)$ during the dry period

\begin{tabular}{lcccc}
\hline Variable & Heat stress & Cooling & SEM & $P$-value \\
\hline Birth weight, kg & 35.7 & 36.3 & 1.5 & 0.79 \\
Grain DMI, kg/d & 0.34 & 0.53 & 0.07 & 0.05 \\
BW, kg & 48.3 & 52.0 & 2.0 & 0.19 \\
Withers height, cm & 78.5 & 79.1 & 0.9 & 0.64 \\
Heart girth, cm & 83.7 & 85.6 & 1.1 & 0.24 \\
Hip height, cm & 82.0 & 81.8 & 1.0 & 0.90 \\
ADG, kg/d & & & & \\
0-28 d & 0.43 & 0.49 & 0.04 & 0.24 \\
29-56 d & 0.49 & 0.78 & 0.07 & 0.02 \\
$0-56 \mathrm{~d}$ & 0.46 & 0.63 & 0.04 & 0.01 \\
\hline
\end{tabular}
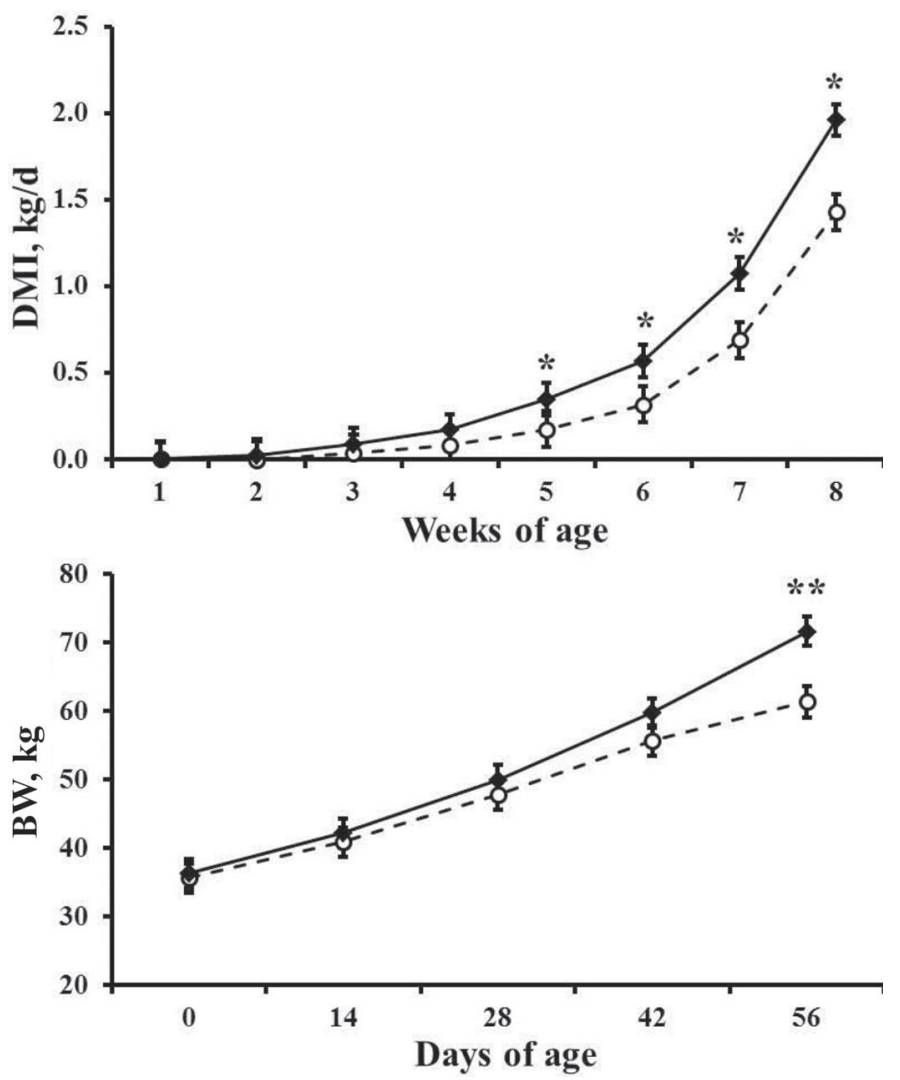

Figure 1. The calf starter DMI and BW of calves born to dams exposed to either heat stress $(n=10)$ or cooling $(n=10)$ during the dry period. Solid diamond $(\bullet)$ and open circles $(O)$ represent cooling and heat stress, respectively. For starter DMI, a treatment effect $(P$ $=0.05)$ and a treatment by time interaction $(P=0.01)$ were found. For BW, a treatment by time interaction $(P<0.01)$ was found, but no treatment effect $(P=0.19)$. ${ }^{* *} P \leq 0.01,{ }^{*} P \leq 0.05$. Error bars indicate SEM.

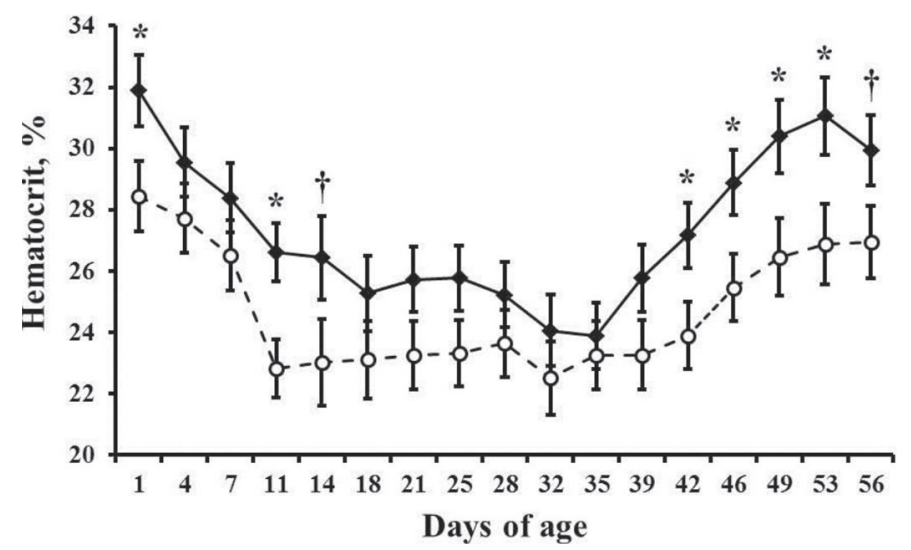

Figure 2. Hematocrit of calves born to dams exposed to either heat stress $(\mathrm{n}=10)$ or cooling $(\mathrm{n}=10)$ during the dry period. Solid diamond $(\checkmark)$ and open circles $(O)$ represent cooling and heat stress, respectively. A tendency was observed for a treatment effect $(P=$ $0.07)$ and a treatment by time interaction $(P=0.04) .{ }^{*} P \leq 0.05, \dagger P$ $\leq 0.10$. Error bars indicate SEM. 
similar basal plasma concentrations of NEFA and BHB before 32 DOA, but elevated plasma NEFA and BHB after $32 \mathrm{DOA}$ (treatment by time interaction: $P<0.05$; Figure 3).

\section{Metabolic Tests}

Relative to those born to CL cows, HS calves had higher $(P<0.01) \mathrm{CR}$ and lower $(P<0.05)$ glucose $\mathrm{AUC}_{60}$ and $\mathrm{AUC}_{120}$, and used less $(P<0.01)$ time to reach half of the maximal glucose concentration after GTT (Table 2, Figure 4). In response to glucose infusion, HS calves tended $(P<0.07)$ to have a higher maximal plasma concentration of insulin relative to CL, but no treatment effects were observed for insulin increment and AUC to GTT (Table 2). During IC, although no differences $(P \geq 0.15)$ were observed for measures of glucose response (Table 3), HS calves had lower $(P=0.02) \mathrm{CR}$, longer $(P=0.04) \mathrm{T}_{1 / 2}$, higher $(P<0.05)$ insulin AUC compared with CL (Table 3,
Figure 5$)$, and a tendency $(P=0.07)$ for treatment by time interaction for $\mathrm{AUC}_{30}$, such that $\mathrm{HS}$ calves had a higher $(P<0.01) \mathrm{AUC}_{30}$ at $8 \mathrm{DOA}$ compared with CL. Additionally, HS calves had a higher $(P=0.04)$ NEFA $\mathrm{AUC}_{60}$ compared with CL (Table 3, Figure 6). No differences $(P>0.10)$ were observed for measures of glucose and NEFA responses to AC, except that maternal HS tended $(P=0.06)$ to lower the increment of plasma concentration of glucose after AC (Table 4).

\section{DISCUSSION}

Similar to previous studies using the same experimental model (Tao et al., 2012b; Thompson et al., 2014), in the current experiment the cooling system was effective in abatement of HS and reduced the heat strain of cows during the dry period, as indicated by the significantly lower rectal temperature and respiration rate of CL cows compared with HS cows. These differences in physiological indicators of HS suggest
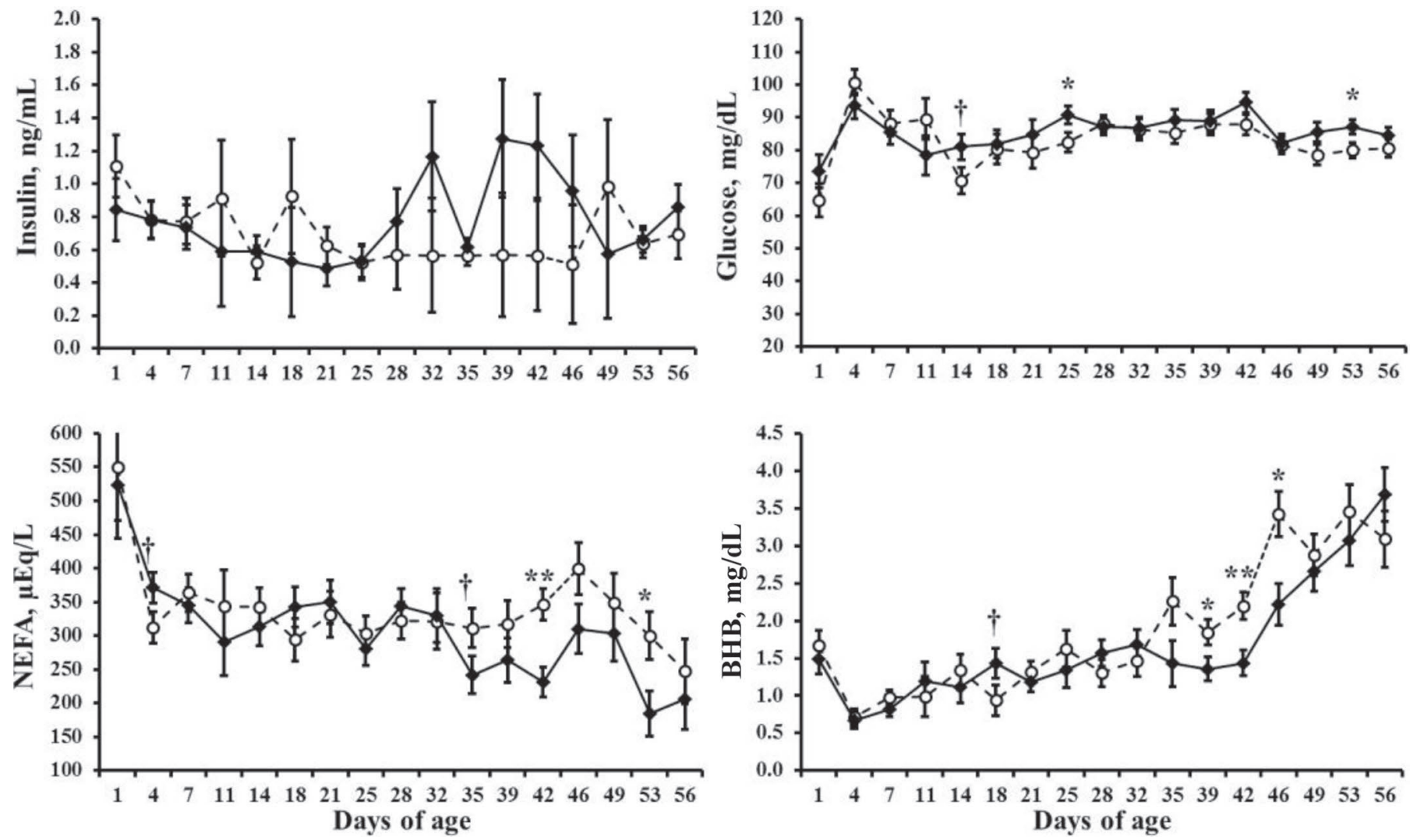

Figure 3. The plasma concentrations of insulin, glucose, nonesterified fatty acids (NEFA), and BHB of calves born to dams exposed to either heat stress $(\mathrm{n}=10)$ or cooling $(\mathrm{n}=10)$ during the dry period. Solid diamond $(\checkmark)$ and open circles $(O)$ represent cooling and heat stress, respectively. For plasma insulin concentration, no effects of treatment $(P=0.96)$ or treatment by time interaction $(P=0.65)$ were found. For plasma glucose concentration, no treatment effect $(P=0.38)$ was observed, but a tendency for treatment by time interaction $(P=0.07)$ was found. For plasma NEFA and BHB concentrations, no treatment effects $(P=0.18$ and $P=0.39$, respectively) were found, but a treatment by time interaction $\left(P=0.02\right.$ and $P=0.04$, respectively) was present. ${ }^{*} P \leq 0.01,{ }^{*} P \leq 0.05, \dagger P \leq 0.10$. Error bars indicate SEM. 
Table 2. Glucose and insulin responses to glucose tolerance tests of calves born to dams exposed to either heat stress (HS, $\mathrm{n}=9$ ) or cooling $(\mathrm{CL}, \mathrm{n}=10)$ during the dry period

\begin{tabular}{|c|c|c|c|c|c|c|c|c|c|c|}
\hline Measure $^{1}$ & \multicolumn{2}{|c|}{$8 \mathrm{~d}$ of age } & \multicolumn{2}{|c|}{$29 \mathrm{~d}$ of age } & \multicolumn{2}{|c|}{$57 \mathrm{~d}$ of age } & SEM & \multicolumn{3}{|c|}{$P$-value } \\
\hline Baseline & 86 & 85 & 86 & 89 & 79 & 88 & 7 & 0.59 & 0.85 & 0.78 \\
\hline Maximum & 187 & 177 & 181 & 190 & 190 & 201 & 8 & 0.69 & 0.23 & 0.31 \\
\hline Increment & 101 & 91 & 94 & 102 & 111 & 113 & 5 & 0.92 & $<0.01$ & 0.14 \\
\hline $\mathrm{CR}, \% / \min$ & 2.06 & 1.30 & 1.20 & 1.04 & 1.55 & 0.90 & 0.13 & $<0.01$ & $<0.01$ & 0.05 \\
\hline $60 \mathrm{~min}$ & 1,285 & 2,010 & 2,391 & 2,724 & 2,619 & 3,247 & 187 & $<0.01$ & $<0.01$ & $\begin{array}{l}0.14 \\
0.44\end{array}$ \\
\hline $120 \min$ & 766 & 1,398 & 2,261 & 2,430 & 2,364 & 3,777 & 410 & 0.03 & $<0.01$ & 0.36 \\
\hline \multicolumn{11}{|l|}{ Insulin, $\mathrm{ng} / \mathrm{mL}$} \\
\hline Baseline & 0.97 & 0.95 & 0.50 & 0.42 & 0.57 & 0.48 & 0.31 & 0.29 & 0.09 & 0.84 \\
\hline Maximum & 3.83 & 3.49 & 1.47 & 0.97 & 2.45 & 1.61 & 0.81 & 0.07 & $<0.01$ & 0.74 \\
\hline Increment & 2.91 & 2.53 & 1.01 & 1.31 & 1.55 & 1.70 & 0.74 & 0.19 & $<0.01$ & 0.95 \\
\hline
\end{tabular}

${ }^{1}$ Baseline $=$ average glucose and insulin concentrations at $-15,-5$, and 0 min during the glucose tolerance test; maximum $=$ the maximal glucose and insulin concentrations; increment $=$ concentration difference between maximum and baseline; $\mathrm{CR}=$ clearance rate of glucose during the first 60 min of the test; $\mathrm{T}_{1 / 2}=$ time to reach half maximal glucose concentration; $\mathrm{AUC}=$ area under the curve.

${ }^{2} \mathrm{TRT}=$ treatment.

that the experimental model produced a maternal uterine environment consistent with hyperthermia and therefore an effective HS treatment was achieved.

Unexpectedly, no difference was found in calf birth weight between treatments, which is in contradiction with previous reports (do Amaral et al., 2011; Tao et al., 2011; Monteiro et al., 2014). Tao et al. (2012a) suggested that the lower birth weight associated with late gestation maternal HS is due to a combination of shorter gestation length, direct effect of fetal hyperthermia, and fetal growth retardation by maternal HS induced impairment of placental function. In this regard, in the current experiment, similar gestation length between HS and CL dams provided fetuses from both groups with similar time to grow. Also, similar calf birth weight between treatments suggests that the extent of changes in the uterine thermo-environment and placental function by maternal HS was not sufficient to reduce the somatic growth of the fetus, or the fetus metabolically adapted to the undesirable uterine environment, or both. Indeed, in the current study, the difference in hematocrit of calves born to HS and CL cows suggests that the in utero environment was altered by maternal HS. Exposure of ewes to HS causes uterine hypoxia (Regnault et al., 2007) due to impaired placental function. Thus, the decreased hematocrit of HS calves relative to CL during the preweaning period may indicate a carryover effect from the adaptation to the reduced uterine oxygen supply caused by maternal
HS. This hypothesis has never been confirmed in a bovine model, but suggests that fetal development was altered by the maternal HS, which in turn influenced calf postnatal performance.

Unlike previous research (Tao et al., 2012a; Monteiro et al., 2014), in which both groups of calves had similar growth rate from birth to weaning, in the current study, heifers born to HS dry cows had lower starter intake and, as a consequence, lower ADG and BW at 56 DOA compared with those from CL dry cows. The reasons for the discrepancy between studies are unknown, but the data in this specific study indicate that maternal HS exerts carryover effects on calf postnatal growth and, perhaps, on nutrient absorption and utilization. Compared with those from CL cows, heifers from HS cows had greater basal plasma concentrations of NEFA and unexpected and surprisingly higher basal BHB concentrations after 32 DOA, without a change in basal plasma insulin. The higher basal NEFA and BHB concentrations of calves born to HS compared with CL dams coincide with the difference in starter intake between treatments, but are in contradiction with the traditional view that a calf with lower starter intake has less ruminal BHB production, and hence a lower plasma BHB concentration (Quigley and Bernard, 1992). These unusual basal plasma metabolite profiles may suggest that calves from HS dams absorb and use less free fatty acid and ketones as energy sources compared with those from CL dams; in other words, to support the higher growth 
rate, CL calves may have taken more NEFA and BHB from blood to provide energy compared with HS. Additionally, these data may indicate that maternal HS alters the calf's preference of energy sources, such that calves from HS cows prefer to use glucose rather than fatty acid or ketones compared with those from CL
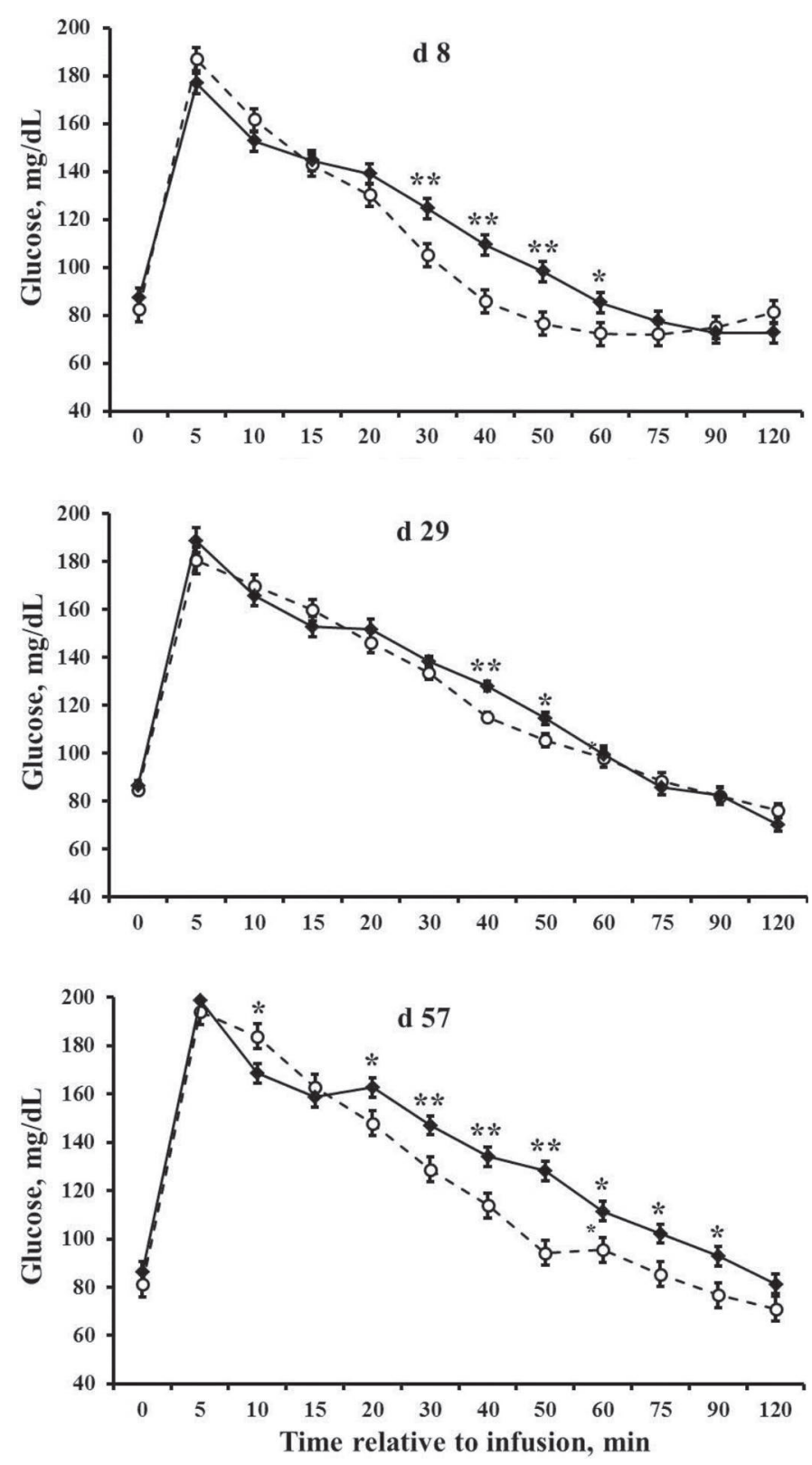

Figure 4. Glucose responses to glucose tolerance test of calves born to dams exposed to either heat stress $(n=9)$ or cooling $(n=10)$ during the dry period, at 8,29 , and $57 \mathrm{~d}$ of age. Solid diamonds ( ) and open circles $(O)$ represent cooling and heat stress, respectively. Effects of treatment $(P=0.16, P=0.42$, and $P=0.02$ at 8,29 , and $57 \mathrm{~d}$ of age, respectively), minute $(P<0.01)$, and treatment by minute interaction $(P<0.01)$. ${ }^{* *} P<0.01,{ }^{*} P<0.05$. Error bars indicate SEM. cows, especially after the percentage of energy provided by starter intake increased. Consistent with that idea, both groups of calves had a similar growth rate during the first 28 DOA days of age, when most of the ingested energy was from milk lactose and lipids. Although no overall treatment effect was observed, the tendency for occasional lower basal plasma glucose concentration during the preweaning period of HS calves relative to CL also suggests a higher preference for glucose utilization. During lactation, the HS dairy cow develops a preference to use glucose as a fuel rather than partitioning it toward milk synthesis (Wheelock et al., 2010). Thus, it seems that maternal HS during late gestation results in a similar phenomenon in the fetus, which carries over into postnatal life. Moreover, the time of blood sample collection could account for some of the difference in blood metabolites observed in the present study. Quigley and Bernard (1992) reported that plasma concentration of $\mathrm{BHB}$ is lower in blood samples collected before feeding compared with 2 $\mathrm{h}$ after feeding, and the difference between treatments (milk vs. solid feeding) is more pronounced at $2 \mathrm{~h}$ after feeding. Thus, the bleeding schedule (before morning feeding) of the current study may also mask some of the potential effects of the different starter intake between HS and CL calves on basal plasma BHB concentration.

Coupled with similar glucose responses, the slower insulin clearance of HS calves after insulin infusion indicate a relatively high level of insulin resistance in peripheral tissues, such as muscle and adipose tissue, and thus limited insulin-mediated glucose entry into the peripheral tissues, compared with CL. Additionally, the slower insulin clearance to IC observed in HS calves relative to CL tended to be more pronounced at an earlier age, such as at 8 DOA, which is consistent with the observation of Tao and Dahl (2013) that calves born to HS dry cows have higher plasma insulin concentration after colostrum ingestion, at $1 \mathrm{~d}$ after birth, compared with those from CL cows. In contrast, Tao et al. (2014) used a similar experimental model as in the current experiment, but observed that weaned calves born to HS dry cows had more rapid glucose but similar insulin clearance after IC compared with those from CL cows. However, different from Tao and Dahl (2013) and the current experiment, in which only heifer calves were used, the experiment conducted by Tao et al. (2014) had a small and unbalanced number of bulls and heifers within each treatment. As reviewed by Kapoor et al. (2006), male and female offspring respond very differently to prenatal stress across different species. Therefore, the discrepancy between studies may indicate that bulls and heifers respond to late gestation maternal HS differently, especially regarding the 
insulin action on peripheral tissues. The physiological and molecular mechanisms of enhanced insulin resistance in the offspring after maternal HS are unknown. In weaned dairy bull calves, hyperthermia induced by HS had no effect on insulin and glucose responses to an IC (O'Brien et al., 2010), indicating that HS has no effect on peripheral insulin resistance in growing cattle. However, for the rapidly growing fetus, the altered uterine environment coupled with fetal hyperthermia due to maternal HS may have different influences on peripheral insulin action. The more pronounced difference in insulin clearance after IC between treatments at an early age is intriguing and may suggest that calves from HS cows gradually adapt to the extra-uterine environment and the tissue insulin resistance induced by maternal HS is diminished as animals grow during postnatal development.

In contrast to the effects on insulin, compared with those from CL cows, heifers born to HS dry cows had a more rapid glucose clearance after glucose infusion with similar insulin responses, which is consistent with the previous observation after weaning (Tao et al., 2014) and suggests a higher capacity for glucose disposal, but similar pancreatic insulin release to glucose stimulation in heifers from HS cows relative to CL during the preweaning period. Glucose tolerance after a GTT is determined by a combination of the insulin response after glucose infusion, insulin sensitivity in peripheral tissues, and the noninsulin-dependent glucose disposal due to a mass action (Kahn et al., 1994). With the similar insulin responses after GTT and higher level of insulin resistance observed in IC, the data in the current study indicate that late gestation maternal HS improves the offspring's postnatal insulin-independent glucose absorption and basal glucose uptake (Kahn et al., 1994), which partly supports the hypothesis that heifers from HS cows have a preference to use glucose as a fuel compared with those from CL cows, as discussed above. Thus, these data suggest an enhanced expression of the noninsulin-dependent glucose transporter (GLUT) in calves from HS dams relative to CL. Among the facilitated GLUT that are insulin indepen-

Table 3. Insulin, glucose, and nonesterified fatty acid (NEFA) responses to insulin challenges of calves born to dams exposed to either heat stress (HS, $\mathrm{n}=9$ ) or cooling (CL, $\mathrm{n}=10)$ during the dry period

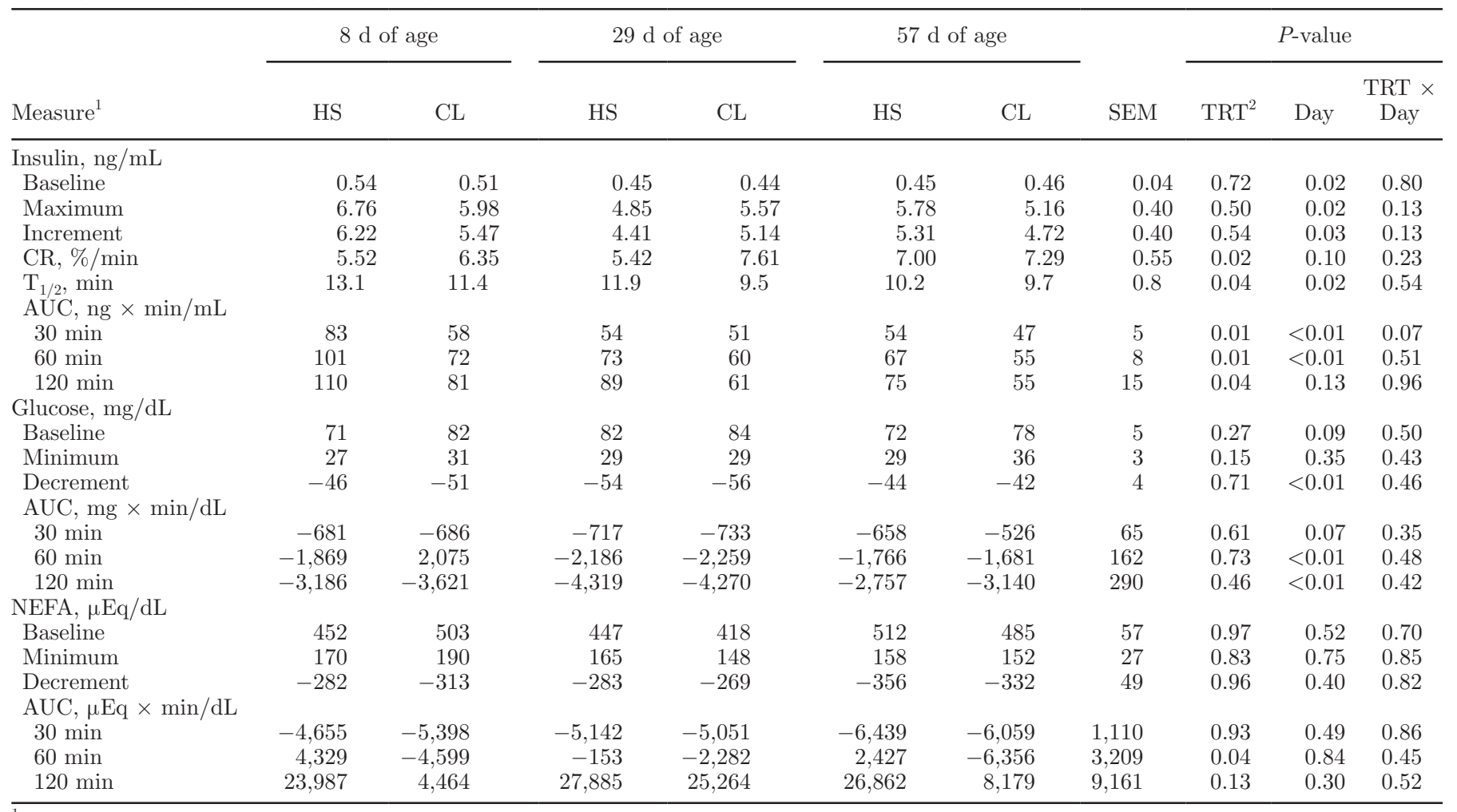

${ }^{1}$ Baseline $=$ average glucose, NEFA, and insulin concentration at $-15,-5$, and 0 min during the insulin challenge; maximum $=$ the maximal insulin concentration; minimum $=$ the minimal glucose and NEFA concentrations. Increment/decrement $=$ concentration difference between maximum/minimum and baseline; $\mathrm{CR}=$ clearance rate of insulin during the first $40 \mathrm{~min}$ of the challenge; $\mathrm{T}_{1 / 2}=$ time to reach half maximal insulin concentration. AUC = area under the curve.

${ }^{2} \mathrm{TRT}=$ treatment 
dent, GLUT1 is the ubiquitous form expressed in cells and tissues and responsible for basal glucose uptake (Hocquette and Abe, 2000; Zhao and Keating, 2007). In contrast to GLUT4, whose expression in muscle and adipose tissue decreases in the calf from birth to $1 \mathrm{yr}$ of
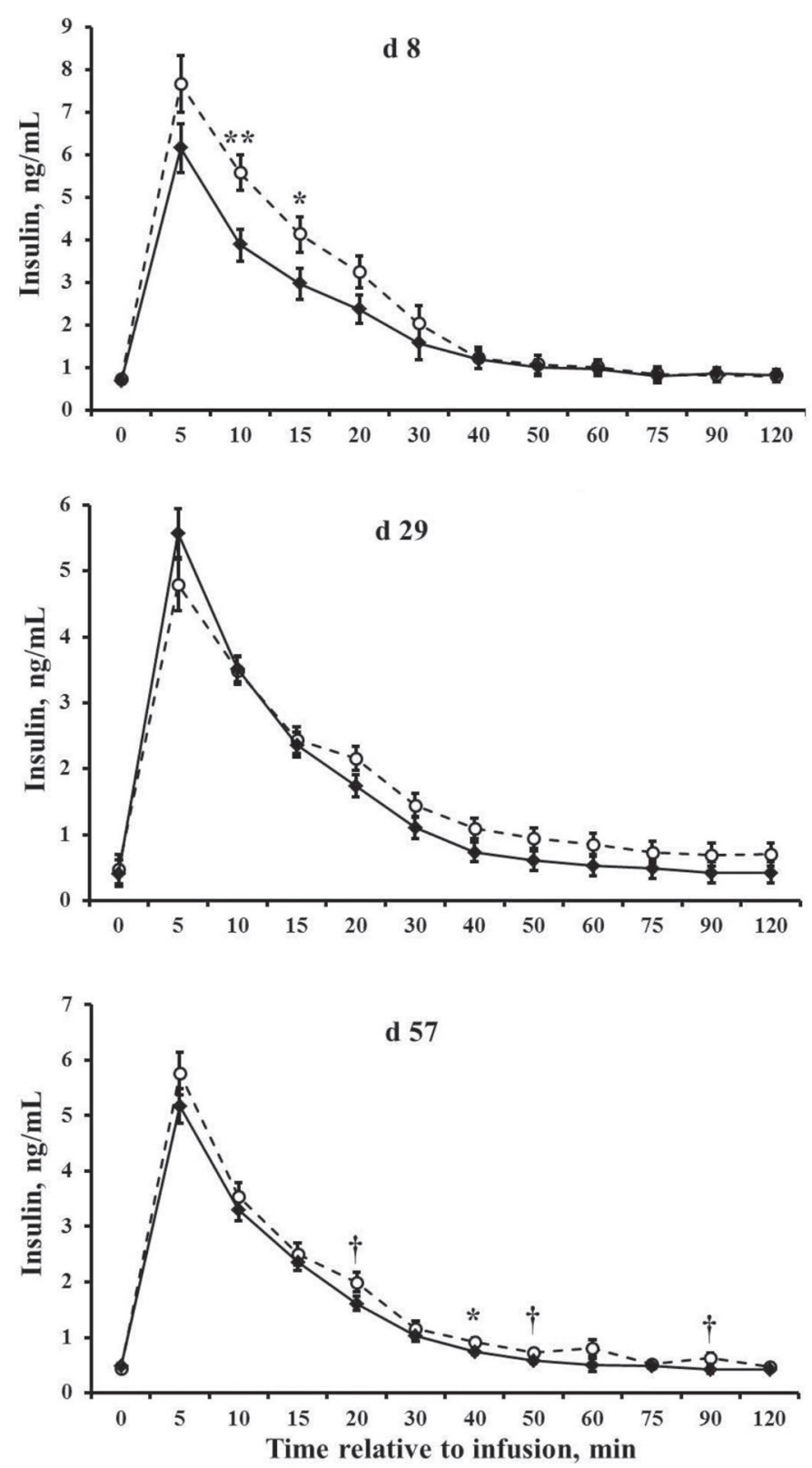

Figure 5. Insulin responses to insulin challenge of calves born to dams exposed to either heat stress $(\mathrm{n}=9)$ or cooling $(\mathrm{n}=10)$ during the dry period, at 8,29 , and $57 \mathrm{~d}$ of age (DOA). Solid diamond $(\bullet)$ and open circles $(O)$ represent cooling and heat stress, respectively. Effects of treatment $(P=0.16, P=0.05$, and $P=0.15$ at 8,29 , and 57 DOA, respectively), minute $(P<0.01)$, and treatment by minute interaction $(P=0.04, P=0.33$, and $P=0.06$ at 8,29 , and $57 \mathrm{DOA}$, respectively). ${ }^{* *} P \leq 0.01,{ }^{*} P \leq 0.05, \dagger P \leq 0.10$. Error bars indicate SEM. age, the protein expression of GLUT1 in peripheral tissues is constant (Abe et al., 2001). Thus, the maternal thermal insult may alter the GLUT1 expression of the fetus and that altered expression profile may persist into postnatal life, at least during the preweaning pe-
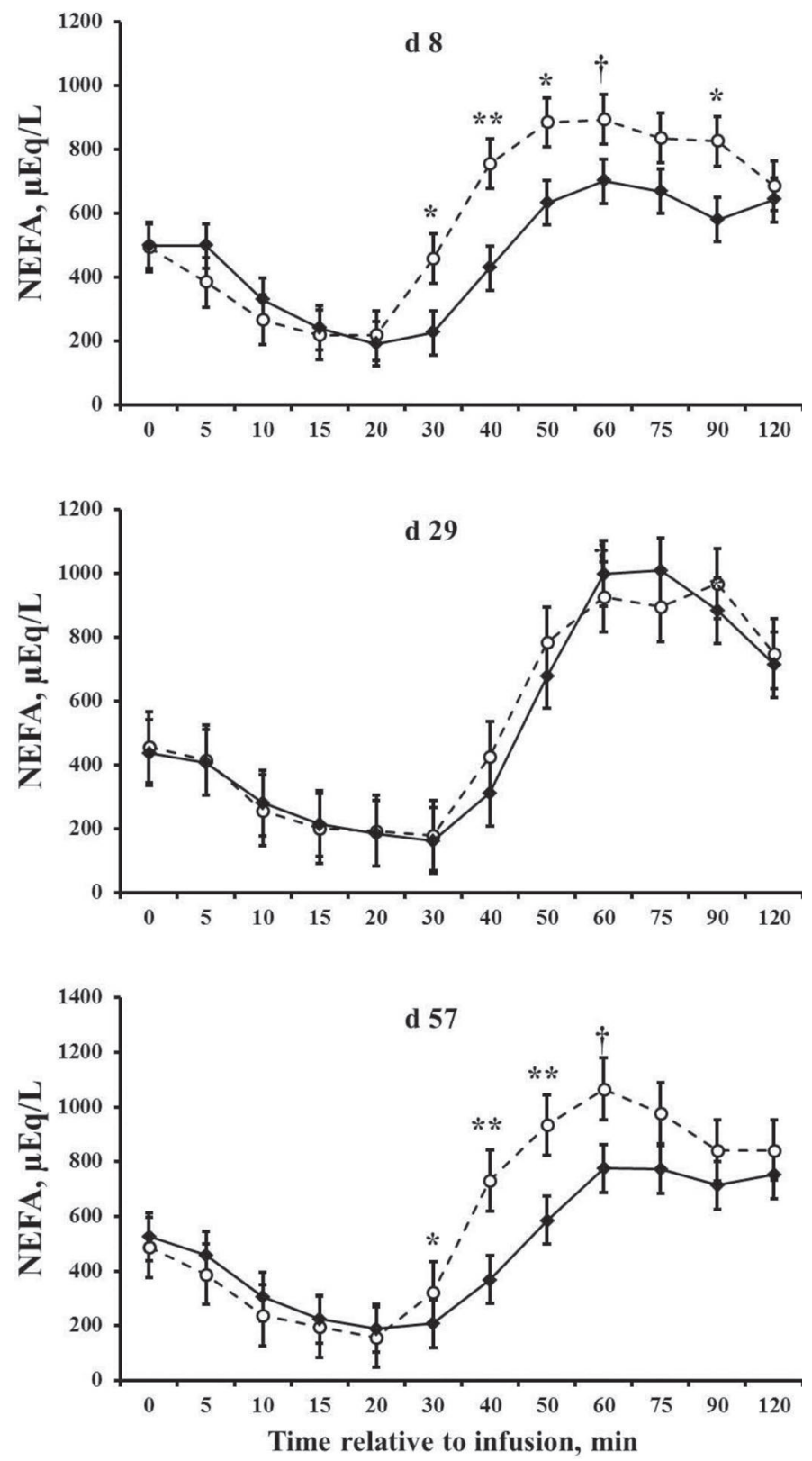

Figure 6. The nonesterified fatty acid (NEFA) responses to insulin challenge of calves born to dams exposed to either heat stress ( $\mathrm{n}=$ $9)$ or cooling $(\mathrm{n}=10)$ during the dry period at 8,29 , and $57 \mathrm{~d}$ of age $(\mathrm{DOA})$. Solid diamond $(\checkmark)$ and open circles $(O)$ represent cooling and heat stress, respectively. Effects of treatment $(P=0.12, P=0.87$, and $P=0.15$ at 8,29 , and 57 DOA, respectively $)$, minute $(P<0.01)$ and treatment by minute interaction $(P=0.03, P=0.99$ and $P=0.03$ at 8,29 and 57 DOA, respectively). ${ }^{* *} P \leq 0.01,{ }^{*} P \leq 0.05, \dagger P \leq 0.10$. Error bars indicate SEM. 
riod. However, the design of the current experiment limits the ability to distinguish the possible different expression of the GLUT on the tissue level, but that question deserves further exploration.

Fatty acid metabolism of the fetus can be altered by in utero environment, and that in turn influences postnatal adipose tissue deposition (Sarr et al., 2012). In the ewe, maternal HS during early to mid-gestation results in decreased expression of $\beta_{2}$-AR mRNA and protein in perirenal adipose tissue and reduces the NEFA release after an AC in the lamb at 21 DOA, suggesting a compromise of adipose tissue mobilization caused by maternal HS during early to mid-pregnancy (Chen et al., 2010). In contrast, in the current experiment, both groups of calves had similar glucose and NEFA responses to AC, which indicates that maternal HS during late gestation in cattle has no effect on adrenaline-mediated fat mobilization and glycogenolysis in the liver of the female offspring, or at least during the preweaning period. The reason for the discrepancy between studies is unknown, but may be due to the species differences, the time frame and extent of maternal HS applied, or a combination of those effects. In addition to epinephrine, fatty acid metabolism is controlled by insulin, which serves as an anti-lipolytic factor and enhances lipogenesis (Hayirli, 2006). In the present study, the similar NEFA response to the IC before the nadir of the NEFA concentration $(\sim 30 \mathrm{~min}$ after IC), suggests that there was no difference between heifers from HS and CL cows regarding insulin action on lipolysis or lipogenesis, whereas the higher response of heifers born to HS cows compared with CL after NEFA nadir may indicate a stronger negative feedback on lipolysis by glucagon and epinephrine after insulin infusion. With the similar NEFA response after AC between HS and CL calves, it is unlikely that the adipose tissue responsiveness to epinephrine plays a role in the observed NEFA response during IC. However, the possibility of a more pronounced epinephrine release after IC in HS calves compared with CL cannot be excluded. Similar to epinephrine, the release of glucagon is increased after a drop in blood glucose concentration to stimulate gluconeogenesis and glycogenolysis and restore the euglycemia, and it also stimulates lipolysis in cattle (De Boer et al., 1986). Thus, increased glucagon release or enhanced adipose tissue responsiveness to glucagon may partly explain the stronger NEFA responses to AC in heifers from HS cows compared with those from CL, but such hypothesis has never been evaluated. Nevertheless, the data indicate that maternal HS during the late gestation alters heifer's fatty acid metabolism in their early life, which, however, is insulin and epinephrine independent.

It has been extensively studied that maternal HS during the dry period impairs calf immunity (Tao et al., 2012a; Monteiro et al., 2014) during the preweaning period and lowers heifer survival later in life (Monteiro et al., 2013). Further, heifers born to dry period HS cows produce less milk during their first lactation compared with those from CL dams (Monteiro et al., 2013); however, the physiological mechanism is still unknown and could result from the altered metabolism. In other

Table 4. Glucose and nonesterified fatty acid (NEFA) responses to adrenaline challenges of calves born to dams exposed to either heat stress $(\mathrm{HS}, \mathrm{n}=9)$ or cooling $(\mathrm{CL}, \mathrm{n}=10)$ during the dry period

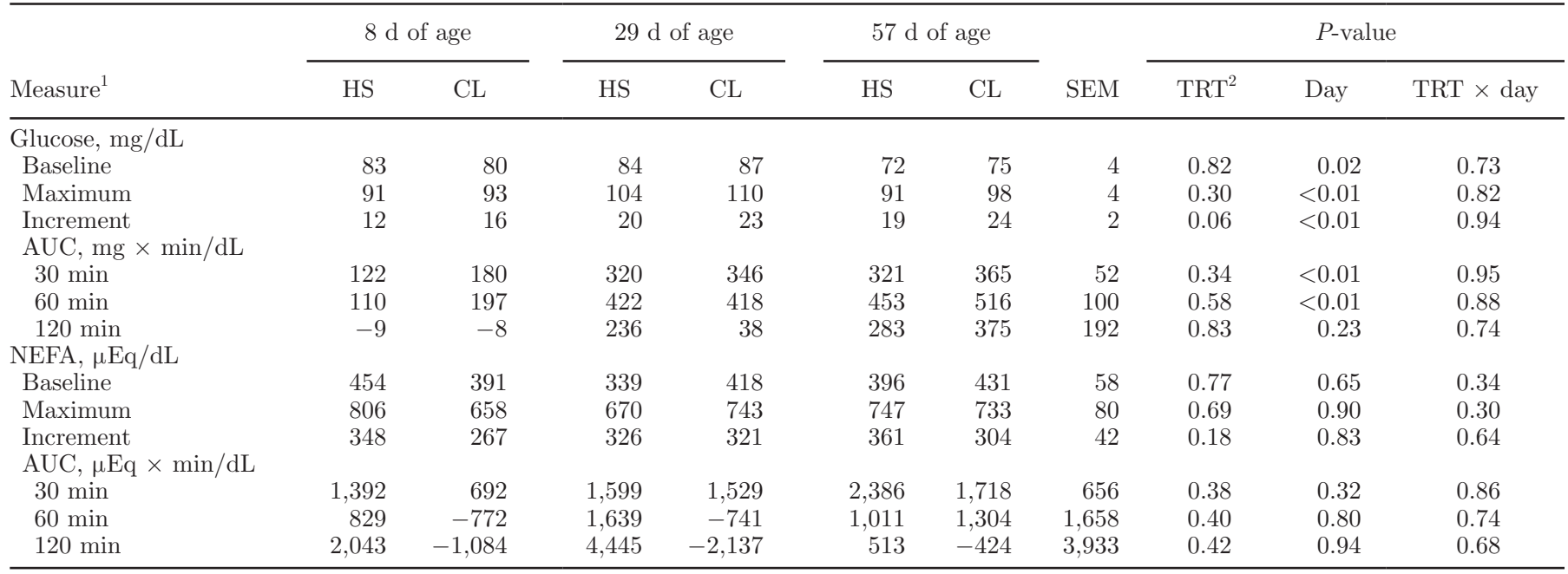

${ }^{1}$ Baseline $=$ average glucose and NEFA concentration at $-15,-5$, and 0 min during the adrenaline challenge; maximum $=$ the maximal glucose and NEFA concentration; increment $=$ concentration difference between maximum and baseline; AUC $=$ area under the curve.

${ }^{2} \mathrm{TRT}=$ treatment. 
livestock species, various maternal insults (Arnott et al., 2012; Antolic et al., 2015), including HS (Chen et al., 2010; Boddicker et al., 2014), alter neonatal metabolism and future performance. Yet, such research in dairy cattle is surprisingly scarce. In the current study, the possible increase in usage of glucose in the heifers born to HS cows compared with CL is intriguing and indicates that late gestation maternal HS influences calf glucose metabolism throughout the entire preweaning period. Abe et al. (2001) reported that GLUT1 protein expression in the peripheral tissues of calves persists during postnatal life up to $1 \mathrm{yr}$ of age, suggesting that the increased glucose uptake associated with late gestation maternal HS may persist into adulthood and, in turn, influence heifer body growth and composition and, perhaps, milk synthesis by limiting the milk lactose biosynthesis during lactation. Further studies need to be conducted to examine the effect of maternal HS on calf metabolism beyond the preweaning period.

\section{CONCLUSIONS}

Maternal HS during the dry period reduces heifer calf grain intake and growth during the preweaning period. Combined with altered basal metabolites profiles, the results from the metabolic tests suggest that heifers born to dry period HS cows have a higher insulinindependent glucose disposal and altered fatty acid metabolism during the postnatal period compared with those from CL cows.

\section{ACKNOWLEDGMENTS}

The authors thank the staff of the Dairy Unit and Calf Unit of the University of Florida for animal care and data collection. The authors also extend their appreciation to Melissa Tawzer, from the University of Georgia, for her help with sample analyses. This project was supported by Federal Hatch, USDA.

\section{REFERENCES}

Abe, H., Y. Kawakita, K. Hodate, and M. Saito. 2001. Postnatal development of glucose transporter proteins in bovine skeletal muscle and adipose tissue. J. Vet. Med. Sci. 63:1071-1075.

Antolic, A., X. Feng, C. E. Wood, E. M. Richards, and M. KellerWood. 2015. Increased maternal nighttime cortisol concentrations in late gestation alter glucose and insulin in the neonatal lamb. Physiol. Rep. 3:e12548-e12561.

Arnott, G., D. Roberts, J. A. Rooke, S. P. Turner, A. B. Lawrence, and K. M. D. Rutherford. 2012. BOARD-INVITED REVIEW: The importance of the gestation period for welfare of calves: Maternal stressors and difficult births. J. Anim. Sci. 90:5021-5034.

Baumgard, L. H., J. B. Wheelock, S. R. Sanders, C. E. Moore, H. B. Green, M. R. Waldron, and R. R. Rhoads. 2011. Postabsorptive carbohydrate adaptations to heat stress and monensin supplementation in lactating Holstein cows. J. Dairy Sci. 94:5620-5633.
Boddicker, R. L., J. T. Seibert, J. S. Johnson, S. C. Pearce, J. T Selsby, N. K. Gabler, M. C. Lucy, T. J. Safranski, R. P. Rhoads, L. H. Baumgard, and J. W. Ross. 2014. Gestational heat stress alters postnatal offspring body composition indices and metabolic parameters in pigs. PLoS ONE 9:e110859.

Chen, X., A. L. Fahy, A. S. Green, M. J. Anderson, R. P. Rhoads, and S. W. Limesand. 2010. $\beta 2$-Adrenergic receptor desensitization in perirenal adipose tissue in fetuses and lambs with placental insufficiency-induced intrauterine growth restriction. J. Physiol. 588:3539-3549.

De Boer, G., A. Trenkle, and J. W. Young. 1986. Secretion and clearance rates of glucagon in dairy cows. J. Dairy Sci. 69:721-733.

Dikmen, S., E. Alava, E. Pontes, J. M. Fear, B. Y. Dikmen, T. A. Olson, and P. J. Hansen. 2008. Differences in thermoregulatory ability between slick-haired and wild-type lactating Holstein cows in response to acute heat stress. J. Dairy Sci. 91:3395-3402.

do Amaral, B. C., E. E. Connor, S. Tao, M. J. Hayen, J. W. Bubolz, and G. E. Dahl. 2010. Heat stress abatement during the dry period influences prolactin signaling in lymphocytes. Domest. Anim. Endocrinol. 38:38-45.

do Amaral, B. C., E. E. Connor, S. Tao, M. J. Hayen, J. W. Bubolz, and G. E. Dahl. 2011. Heat stress abatement during the dry period influences metabolic gene expression and improves immune status in the transition period of dairy cows. J. Dairy Sci. 94:86-96.

Hayirli, A. 2006. The role of exogenous insulin in the complex of hepatic lipidosis and ketosis associated with insulin resistance phenomenon in postpartum dairy cattle. Vet. Res. Commun. 30:749-774.

Hayirli, A., D. R. Bremmer, S. J. Bertics, M. T. Socha, and R. R. Grummer. 2001. Effect of chromium supplementation on production and metabolic parameters in periparturient dairy cows. J. Dairy Sci. 84:1218-1230.

Hocquette, J.-F., and H. Abe. 2000. Facilitative glucose transporters in livestock species. Reprod. Nutr. Dev. 40:517-533.

Hostettler-Allen, R. L., L. Tappy, and J. W. Blum. 1994. Insulin resistance, hyperglycemia, and glucosuria in intensively milk-fed calves. J. Anim. Sci. 72:160-173.

Kahn, S. E., R. L. Prigeon, D. K. McCulloch, E. J. Boyko, R. N. Bergman, M. W. Schwartz, J. L. Neifing, W. Kenneth Ward, J. C. Beard, J. P. Palmer, and D. Porte Jr.. 1994. The contribution of insulin-dependent and insulin-independent glucose uptake to intravenous glucose tolerance in healthy human subjects. Diabetes 43:587-592.

Kapoor, A., E. Dunn, A. Kostaki, M. H. Andrews, and S. G. Matthews. 2006. Fetal programming of hypothalamo-pituitary-adrenal function: Prenatal stress and glucocorticoids. J. Physiol. 572:3144.

Malven, P. V., H. H. Head, R. J. Collier, and F. C. Buonomo. 1987. Periparturient changes in secretion and mammary uptake of insulin and in concentrations of insulin and insulin-like growth factors in milk of dairy cows. J. Dairy Sci. 70:2254-2265.

Monteiro, A. P. A., S. Tao, I. M. Thompson, and G. E. Dahl. 2013. Effect of heat stress in utero on calf performance and health through the first lactation. J. Anim. Sci. 91(Suppl. 2):184. (Abstr.)

Monteiro, A. P. A. S. Tao, I. M. Thompson, and G. E. Dahl. 2014 Effect of heat stress during late gestation on immune function and growth performance of calves: Isolation of altered colostral and calf factors. J. Dairy Sci. 97:6426-6439.

O'Brien, M. D., R. P. Rhoads, S. R. Sanders, G. C. Duff, and L. H Baumgard. 2010. Metabolic adaptations to heat stress in growing cattle. Domest. Anim. Endocrinol. 38:86-94.

Quigley, J. D., and J. K. Bernard. 1992. Effects of nutrient source and time of feeding on changes in blood metabolites in young calves. J. Anim. Sci. 70:1543-1549.

Regnault, T. R. H., B. de Vrijer, H. L. Galan, R. B. Wilkening, F. C. Battaglia, and G. Meschia. 2007. Development and mechanisms of fetal hypoxia in severe fetal growth restriction. Placenta 28:714723.

Sarr, O., K. Yang, and T. R. H. Regnault. 2012. In utero programming of later adiposity: The role of fetal growth restriction. J. Pregnancy 2012:134758. 
Stanley, C. C., C. C. Williams, B. F. Jenny, J. M. Fernandez, H. G. Bateman II, W. A. Nipper, J. C. Lovejoy, D. T. Gantt, and G. E. Goodier. 2002. Effects of feeding milk replacer once versus twice daily on glucose metabolism in Holstein and Jersey calves. J. Dairy Sci. 85:2335-2343

Tao, S., J. W. Bubolz, B. C. do Amaral, I. M. Thompson, M. J. Hayen, S. E. Johnson, and G. E. Dahl. 2011. Effect of heat stress during the dry period on mammary gland development. J. Dairy Sci. 94:5976-5986.

Tao, S., and G. E. Dahl. 2013. Invited review: Heat stress impacts during the dry period on dry cows and their calves. J. Dairy Sci. 96:4079-4093.

Tao, S., A. P. Monteiro, I. M. Thompson, M. J. Hayen, and G. E. Dahl 2012a. Effect of late gestation maternal heat stress on growth and immune function of dairy calves. J. Dairy Sci. 95:7128-7136.

Tao, S., A. P. A. Monteiro, M. J. Hayen, and G. E. Dahl. 2014. Short communication: Maternal heat stress during the dry period alters whole body insulin response of calves postnatally. J. Dairy Sci. 97:897-901.

Tao, S., I. M. Thompson, A. P. A. Monteiro, M. J. Hayen, L. J. Young, and G. E. Dahl. 2012b. Effect of cooling heat-stressed dairy cows during the dry period on insulin response. J. Dairy Sci. 95:50355046 .

Thompson, I. M., S. Tao, A. P. Monteiro, K. C. Jeong, and G. E. Dahl. 2014. Effect of cooling during the dry period on immune response after Streptococcus uberis intramammary infection challenge of dairy cows. J. Dairy Sci. 97:7426-7436.

Wheelock, J. B., R. P. Rhoads, M. J. VanBaale, S. R. Sanders, and L. H. Baumgard. 2010. Effects of heat stress on energetic metabolism in lactating Holstein cows. J. Dairy Sci. 93:644-655.

Yari, M., A. Nikkhah, M. Alikhani, M. Khorvash, H. Rahmani, and G. R. Ghorbani. 2010. Physiological calf responses to increased chromium supply in summer. J. Dairy Sci. 93:4111-4120.

Yates, D. T., A. S. Green, and S. W. Limesand. 2011. Catecholamines mediate multiple fetal adaptations during placental insufficiency that contribute to intrauterine growth restriction: Lessons from hyperthermic sheep. J. Pregnancy 2011:740408.

Zhao, F-Q., and A. F. Keating. 2007. Expression and regulation of glucose transporters in the bovine mammary gland. J. Dairy Sci. 90(E. Suppl.):E76-E86. 